movement is small, and, where there is a density difference between the phases, sedimentation is the main rate-determining factor in the coagulation process $^{8}$ (for example, benzene in water).

$33^{\prime}$ Ditolyl can be prepared by the method of Ullmann and Meyer?, by heating $m$-iodotoluene with activated copper powder. The yield is poor, the product of doubtful quality and purification difficult. The method is inferior to that described by Mai and by Adams and Kornblum ${ }^{8}$, involving the deamination of $o$-tolidinetetrazonium chloride with hypophos. phorous acid, which gives yields of 70-80 per cent. This method (also described in "Organic Syntheses" 9 ) is claimed to yield a pale yellow viscous oil of $n_{D}(20 \cdot 0)=1.5945$. The ditolyl, the properties of which are tabulated above, was colourless after repeated low-pressure distillation $(c .1 \mathrm{~mm}$. mercury ; b.p. c. $130^{\circ}$ C.) and does not become coloured upon standing. Any yellow product which distils over during the first low-pressure distillation can be easily removed by passing a 5-10 per cent solution in benzene through a short alumina column, on which the coloured compound is strongly adsorbed as a bright red band. The ditolyl is easily eluted from the column, and subsequent low-pressure distillations yield a colourless, viscous oil, which distils unchanged. The ditolyl appears to supercool to $-16^{\circ} \mathrm{C}$. before erystallizing into a white mass, but when solid melts at $5^{\circ} \mathrm{C} .{ }^{10}$.

Department of Chemistry,

University, Sheffield 10. Dec. 19.

${ }^{1}$ Sibree, Trans. Farad. Soc., 28, 27 (1930); 27, 160 (1931).

"Denbigh, Trans. Farad. Soc., 36, $136(1940)$. ,", 203.

- Pickett, Walter and France, J. Amer. Chem. Soc., 58, 2296 (1936). ${ }_{5}^{5}$ O'Shaughnessy and Rodebush, J. Amer. Chem. Soc., 62, 2906 (1940). ${ }^{-}$Lawrence, Chem. and Indust., 615 (1948).

"Ullmann and Meyer, Ann., 43, 332 (1904).

'Mai, Ber., 35, 162 (1902). Adams and Kornblum, .J. Amer. Chem. Soc., 63, 188 (1941).

" "Organic Syntheses", 21, 32.

10 Schultz, Rohde and Vicari, Ann., 352, 119 (1907).

\section{Absorptiometric Determination of Tin by means of Dithiol}

CLARK's method ${ }^{1,2}$ for determining very small amounts of tin makes use of the red-coloured suspension produced when dithiol (4-methyl-1,2-dimercaptobenzene) is warmed with an acid solution containing the tin. In its present form, the method has a serious disadvantage, in that it is necessary to compare visually the depth of colour (with that of standards) by means of reflected light. This technique imposes an unduly low limit on the precision obtainable, and full advantage of this promising method will not be gained until it can be adapted for photo-electric absorptiometry.

In his original investigation, Clark ${ }^{2}$ attempted to measure the suspension by means of transmitted light, but concluded that more satisfactory results could be obtained with this system using reflected light. In order to stabilize the suspension, Clark incorporated some agar jelly, and this procedure has been followed by many subsequent workers. The addition of agar jelly itself tends to preclude the use of the absorptiometric technique owing to its own high and variable density. Gum arabic has been used by Stone $^{3}$; but the use of reflected light was recommended in this case also. De Giacomi ${ }^{4}$ used no dispersing agent; but again reflected light was deemed necessary.
We find that in the absence of any dispersing agent the suspension settles out too quickly to obtain aceurate readings; but during a study of the effect of various modern dispersing agents it was found by one of us (C. K.) that 'Belloid T.D.', a sulphonated condensation product of naphthalene and formaldehyde marketed in solid form by the Geigy Co., Ltd., will not only stabilize the suspension for an hour or two, but also will render the system quite suitable for treatment by absorption spectrophotometry.

Several other dispersing agents have since been tried; but all except one were found to interfere with the reaction. The exception was 'Dispersol L', marketed in liquid form by Imperial Chemical Industries, Ltd., which has a composition similar to that of 'Belloid T.D.'.

The system can be stabilized up to a concentration of at least $10 \mu \mathrm{gm}$. per $\mathrm{ml}$. An absorption maximum occurs in that region of the spectrum isolated by Ilford No. 605 filter.

It is proposed to submit a fuller account of this work for publication elsewhere. This note is published by kind permission of the Admiralty.

C. KENYON

T. C. J. OVENSTON

Admiralty Materials Laboratory, Holton Heath, Poole, Dorset. Dec. 18.

${ }^{1}$ Clark, R. E. D., Analyst, 61, 242 (1936).

2 Clark, R. E. D., Analyst, 62, 661 (1937).

${ }^{3}$ Stone, I., Indust, Eng. Chem., Anal. Ed., 13, 791 (1941).

4 de Giacomi, R., Analyst, 65, 216 (1940).

\section{Exchange of Carbon-I3 Dioxide between Solid Carbonates and Gaseous Carbon Dioxide}

IN a recent communication by Haul, Stein and Louw $^{1}$, results were given of experiments on the exchange between carbon dioxide and solid carbonates, using carbon-13 as a tracer.

Since the results of these experiments were calculated on a comparative basis, no corrections for background and oxygen-17 were made to the ${ }^{13} \mathrm{C} /{ }^{12} \mathrm{C}$ ratios. However, as in these experiments carbon dioxide from various sources was measured, it may be of interest to give the corrected values as well.

Thus, for carbon dioxide generated from 'Analar' barium carbonate (British Drug Houses, Ltd.) with perchloric acid, a value of 1.23 for the atomic per cent of carbon-13 was found, corresponding to a corrected figure of $1 \cdot 13$. A mixture of approximately equal amounts of this carbon dioxide with carbon dioxide from thermally decomposed dolomite gave a value of $1 \cdot 24$, which is corrected to $1 \cdot 14$. The mass spectrometer was at the same time checked with carbon dioxide generated from 'dry ice' (prepared from molasses by fermentation) and a corrected value of 1.09 per cent carbon-13 was obtained. These figures are in agreement with the findings of Murphy and $\mathrm{Nier}^{2}$, namely, that the heavier isotope seams to be preferred in mineral carbonates.

R. A. W. HaUl

L. H. STEIN

National Chemical Research Laboratory, J. D. Louw

National Physical Laboratory,

S.A. Council for Scientific and Industrial Research, Pretoria.

${ }^{1}$ Haul, R. A. W., Stein, L. H., and Louw, J. D., Nature, 167, 241 (1951).

${ }^{2}$ Murphy, B. F., and Nier, A. O., Phys. Rev., 59, 771 (1941). 